\title{
PENGARUH DESAIN PRODUK DAN HARGA TERHADAP KEPUTUSAN PEMBELIAN MOTOR YAMAHA NMAX (Survei Pada Konsumen Fortuna Motor Tasikmalaya)
}

\author{
Roby Abdul Wahab, SM ${ }^{1}$ \\ Budhi Wahyu Fitriadi, S.E, MP.² \\ Suci Putri Lestari, $\mathrm{MM}^{3}$ \\ Email: robyabdul1231@gmail.com \\ Universitas Perjuangan Tasikmalaya ${ }^{1,2,3}$
}

\section{Abstract}

This study was conducted to determine the effect of Product Design and Price on Purchasing Decisions of Yamaha NMax Motorbikes at Fortuna Motor Tasikmalaya. This research uses quantitative descriptive methods. The sampling technique used in this study is the nonprobability sampling technique by purposive sampling. Primary data sources were obtained from distributing questionnaires.

The results showed the Product Design, Price and Purchasing Decisions of the Yamaha NMax in the Fortuna Motor Tasikmalaya as a whole were in the good category. Product design and price simultaneously have a significant effect on the decision to buy a Yamaha NMAX at Fortuna Motor Tasikmalaya. Product design partially has a significant effect on the Purchase Decision of Yamaha NMAX at Fortuna Motor Tasikmalaya. The price partially has a significant effect on the decision to purchase a Yamaha NMAX at Fortuna Motor Tasikmalaya.

\section{Keywords :Product Design, Price and purchase decisions}

\begin{abstract}
Abstrak
Penelitian ini dilakukan untuk mengetahui besar pengaruh Desain Produk dan Harga terhadap Keputusan Pembelian Motor Yamaha NMax di Fortuna Motor Tasikmalaya. Penelitian ini menggunakan metode deskriptif kuantitatif. Teknik sampling yang digunakan dalam penelitian ini adalah teknik nonprobability sampling
\end{abstract}


dengan cara purposive sampling. Sumber data primer diperoleh dari penyebaran kuesioner.

Hasil penelitian menunjukkan Desain Produk, Harga dan Keputusan Pembelian Motor Yamaha NMax di Fortuna Motor Tasikmalaya secara keseluruhan dalam kategori baik. Desain Produk dan Harga secara simultan berpengaruh signifikan terhadap Keputusan Pembelian Motor Yamaha NMAX di Fortuna Motor Tasikmalaya. Desain Produk secara parsial berpengaruh signifikan terhadap Keputusan Pembelian Motor Yamaha NMAX di Fortuna Motor Tasikmalaya. Harga secara parsial berpengaruh signifikan terhadap Keputusan Pembelian Motor Yamaha NMAX di Fortuna Motor Tasikmalaya.

\section{Kata Kunci : Desain Produk, Harga dan Keputusan Pembelian}

\section{PENDAHULUAN}

Pertumbuhan konsumen sepeda motor meningkat luar biasa. Di tengah- tengah persaingan yang begitu tajam akibat banyaknya merek pendatang baru sepeda motor Yamaha yang sudah lama berada di Indonesia dengan segala keunggulannya, cukup mendominasi pasar dan memenuhi kebutuhan angkutan yang tangguh, irit dan ekonomis.Yamaha mulai mengembangkan teknologi yang mampu memenuhi kebutuhan pelanggan yaitu mesin bandel dan irit bahan bakar sehingga menjadikannya sebagai pelopor kendaraan roda dua yang ekonomis.Dalam penelitian ini harga sebagai kemampuan seseorang dalam menilai suatu barang dengan satuan alat ukur rupiah untuk dapat membeli produk yang ditawarkan Fortuna Motor adalah salah satu perusahaan yang bergerak dibidang Otomotif dengan menjual produk kendaran roda dua dari Yamaha mulai sekuter metik hingga motor sport, dan lain-lain yang berhubungan dengan Otomotif.

Sejak pertama kali didirikan Fortuna Motor telah menerapkan desain produk dan harga dalam aktivitas usahanya. Keputusan pembelian di Fortuna Motor hingga kini sudah mengalami kemajuan sejak didirikan tapi tetap saja ada sebagian konsumen yang belum puas akan produk yang dihasilkan sehingga perusahaan akan terus meningkatkan keputusan pembelian demi mendapatkan citra yang baik dan menjadikan Fotuna Motor perusahaan Otomotif bergengsi di kota Tasikmalaya yang selalu mengutamakan desain produknya. Oleh karena itu, dengan diterapkannya kebijakan akan desain produk dan 
p-ISSN : 2714-8319,e-ISSN: 2714-7452

harga diharapkan akan berpengaruh terhadap keputusan pembelian yang dihasilkan. Akan tetapi sampai saat ini belum diketahui pengaruh desain produk dan harga terhadap Keputusan Pembelian.

Maka dari itu, perlu dilakukan suatu penelitian mengenai bagaimana pelaksanaan desain produk dan harga di Fortuna Motor serta bagaimana pengaruhnya terhadap keputusan pembelian dimana hasil penelitian tersebut akan dituangkan dalam usulan penelitian dengan judul "Pengaruh Desain Produk dan Harga terhadap Keputusan Pembelian Motor Yamaha NMax di Fortuna Motor Tasikmalaya"

\section{TINJAUAN PUSTAKA}

\section{Desain Produk}

Menurut Phillip Kotler dan Gerry Amstrong (2012:273), Desain produk adalah Konsep yang lebih besar dari pada gaya. Gaya hanya menggambarkan penampilan produk. Gaya bisa menarik atau membosankan. Gaya yang sensasional bisa menarik perhatian dan menghasilkan estetika yang indah, tetapi gaya tersebut tidak benar-benar membuat kinerja produk menjadi lebih baik. Tidak seperti gaya, desain tidak hanya sekedar kulit luar, desain adalah jantung produk.

\section{Dimensi Desain Produk}

Phillip Kotler dan Gerry Amstrong (2012:255) menyatakan bahwa desain mempunyai enam dimensi yang mencakup bentuk, fitur, mutu, daya tahan, keandalan, mudah diperbaiki dan gaya

\section{Harga}

Harga menurut Daryanto (2013:62) mendefinisikan harga sebagai jumlah uang yang dibagikan untuk suatu produk atau sejumlah nilai yang dipertukarkan konsumen untuk manfaat memiliki atau menggunakan produk.

\section{Indikator Harga}

Menurut Kotler dan Keller (2012:76), terdapat lima dimensi harga, yaitu :
1) Harga Terjangkau
2) Harga wajar 
3) Harga diskon

4) Harga pesaing

5) Kesesuaian harga dengan spesifikasi

\section{KEPUTUSAN PEMBELIAN}

Definisi keputusan pembelian menurut Kotler dan Keller (2016:198) adalah sebagai berikut :

"Keputusan pembelian merupakan tahap evaluasi konsumen dalam membentuk preferensi dimana konsumen telah memiliki pilihan diantara merek-merek dan mungkin juga berbentuk niat untuk membeli merek yang disukai."

Berdasarkan penelitian sebelumnya yang dilakukan oleh Djatmiko et al. (2015), bahwa dimensi-dimensi yang bisa digunakan dalam mengukur keputusan pembelian seperti Cognitive, Affective dan Conative.

\section{METODE PENELITIAN}

Metode yang digunakan ialah metode deskriptif dan Survei. Populasi dalam penelitian ini adalah Konsumen di Fortuna Motor Tasikmalaya yang tidak diketahui. Sampel dalam penelitian ini adalah 100 konsumen Fortuna Motor Tasikmalaya.Data primer dan data sekunder. Data ini untuk mendukung informasi primer maupun dari observasi langsung ke lapangan.Teknik pengumpulan data pada penelitian ini adalah Wawancara dan Menyebarkan kuesioner. Alat analisis yang digunakan adalah analisis regresi berganda.

\section{HASIL PENELITIAN DAN PEMBAHASAN}

\section{Karakteristik Responden}

Sekitar 77 orang atau 77\% responden di dominasi oleh jenis kelamin lakilaki, dan sisanya sebesar 23 orang atau 23\% berjenis kelamin perempuan. Artinya, mayoritas konsumen pengguna Yamaha NMax di Fortuna Motor Tasikmalaya lebih diminati oleh kaum laki-laki dibanding dengan kaum perempuan.

Sekitar 83 orang atau 83\% responden di dominasi oleh usia 21-26 tahun, dan sisanya sebesar 17 orang atau 17\% usia 15-20 tahun 7 orang dan $>56$ tahun 10 
orang. Dilihat dari rentang usia responden, mayoritas responden berada pada rentang usia produktif.

Sekitar 40 orang atau $40 \%$ responden di dominasi oleh wiraswasta, dan sisanya sebesar 60 orang atau $60 \%$ swasta 30 orang, PNS 15 orang, dan lain-lain 15 orang.

\section{Pembahasan}

Berdasarkan hasil perhitungan SPSS 24, dapat dibuat persamaan regresi berganda penelitian sebagai berikut :

$$
\mathrm{Y}=5,943+0,192 \mathrm{X}_{1}+0,212 \mathrm{X}_{2}+\mathrm{e}
$$

Dalam persamaan diatas, konstanta sebesar 5,943. Hal ini berarti jika tidak ada perubahan desain produk $\left(\mathrm{X}_{1}\right)$ dan harga $\left(\mathrm{X}_{2}\right)$ yang mempengaruhi, maka keputusan pembelian (Y) sebesar 5,943. Persamaan regresi tersebut menyatakan bahwa variabel bebas desain produk $\left(\mathrm{X}_{1}\right)$ dan harga $\left(\mathrm{X}_{2}\right)$ menunjukkan nilai positif, artinya memiliki korelasi yang positif. Maka dapat disimpulkan bahwa desain produk dan harga berdampak positif terhadap keputusan pembelian.

Nilai koefisien regresi variabel desain produk $\left(\mathrm{X}_{1}\right)$ sebesar 0,192 adalah positif, artinya bila terjadi peningkatan 1 satuan variabel desain produk $\left(\mathrm{X}_{1}\right)$ dimana faktor-faktor lain konstan, akan dapat meningkatkan keputusan pembelian sebesar 0,192. Nilai koefisian regresi variabel harga $\left(\mathrm{X}_{2}\right)$ sebesar 0,212 adalah positif, artinya bila terjadi peningkatan 1 satuan variabel harga $\left(\mathrm{X}_{2}\right)$ dimana faktor-faktor lain konstan, akan dapat meningkatkan keputusan pembelian sebesar 0,212.

Berdasarkan hasil perhitungan SPSS 24, diperoleh R (korelasi) sebesar 0,627 artinya terdapat korelasi atau keeratan hubungan yang positif antara desain produk, harga terhadap keputusan pembelian Motor Yamaha NMax di Fortuna Motor Tasikmalaya. Berdasarkan penafsiran korelasi yang telah dikemukakan maka terdapat hubungan positif desain produk dan harga terhadap keputusan pembelian Motor Yamaha NMax di Fortuna Motor Tasikmalaya termasuk dalam kategori kuat.

Hasil perhitungan diperoleh dari $\mathrm{R}^{2}$ (koefisien determinasi) sebesar 0,393, dari angka tersebut dapat dicari besarnya koefisien determinasi yang menunjukan besar pengaruh desain produk dan harga terhadap keputusan pembelian Motor Yamaha NMax di Fortuna Motor Tasikmalaya sebesar 39,3\%. Sedangkan faktor 
p-ISSN : 2714-8319,e-ISSN: 2714-7452

lain yang tidak diteliti yang mempengaruhi keputusan pembelian Motor Yamaha NMax di Fortuna Motor Tasikmalaya sebesar 60,7\% yaitu pengenalan kebutuhan, pencarian informasi, evaluasi alternatif, dan perilaku pascapembelian (Kotler dan Armstrong, 2016:183).

Berdasarkan hasil perhitungan SPSS versi 24, diperoleh nilai $F_{\text {hitung }}$ sebesar 31,425 dengan nilai Sig. 0,000, sedangkan nilai $F_{\text {Tabel }}$ 3,090. Ternyata $F_{\text {hitung }}>F_{\text {Tabel }}$ atau cukup dilihat dari nilai Sig. 0,000 yang lebih kecil dari 0,05 ( $\alpha$ ). Dengan demikian Tolak Ho Terima Ha.Hal ini berarti desain produk dan harga, secara simultan berpengaruh signifikan terhadap keputusan pembelian.

Dengan demikian bahwa desain produk dan harga menjadi faktor yang sangat berpengaruh secara nyata dan kuat pada keputusan konsumen untuk melakukan pembelian. Kebijakan penetapan harga selalu dikaitkan dengan kesesuaian dari manfaat yang diterima konsumen. dan hal yang tak kalah penting untuk diperhatikan oleh perusahaan dalam bersaing adalah desain. Desain harus berfungsi sebagai alat komunikasi dan strategi untuk mendapatkan posisi pasar yang menjadi target sasaran yang berujung pada keputusan pembelian.

Dari hasil uraian atas tanggapan responden mengenai desain produk, harga terhadap keputusan pembelian, maka diuraikan mengenai perhitungan statistik yang dapat menerangkan ada tidaknya pengaruh secara simultan antara desain produk, harga terhadap keputusan pembelian.

Hasil penelitian ini relevan dengan penelitian yang dikemukakan oleh Laksmi Saraswati (2015) yang berjudul Pengaruh Desain Produk, Kualitas Produk, Dan Harga Terhadap Keputusan Pembelian Pada Kampung Batik Wiradesa, menunjukkan bahwa desain produk, kualitas produk dan harga secara simultan berpengaruh signifikan terhadap keputusan pembelian.

Nilai koefisien korelasi antara desain produk dengan keputusan pembelian sebesar 0,244. Nilai koefisien korelasi yang positif menunjukkan bahwa desain produk dengan keputusan pembelian memiliki hubungan yang positif. Artinya, bagusnya desain produk yang ditawarkan Motor Yamaha NMax maka semakin baik pula keputusan pembelian pada Motor Yamaha NMax, dan begitu sebaliknya. Sedangkan besar pengaruh ragam produk terhadap keputusan pembelian secara parsial sebesar 5,95\% $\left[\mathrm{Kd}=(0,244)^{2} \times 100 \%\right]$. 
p-ISSN : 2714-8319,e-ISSN: 2714-7452

Untuk mengetahui signifikasi pengaruh desain produk secara parsial terhadap keputusan pembelian dilihat dengan cara membandingkan nilai tabel dengan $t_{\text {hitung. }}$. Hasil perhitungan memberikan nilai $t_{\text {hitung }}=2,474$ dan $t_{\text {tabel }}=1,98447$ $(\alpha=5 \%)$ maka nilai $t_{\text {hitung }}>\mathrm{t}_{\text {tabel }}$ atau 2,474>1,98447 atau dapat juga dilihat dari nilai Sig. 0,015 hasil perhitungan SPSS Versi 24 yang lebih kecil dari 0,05 (nilai $\alpha$ $=5 \%$ ). Dengan demikian Ho ditolak atau Ha diterima, yang berarti bahwa desain produk, secara parsial berpengaruh signifikan terhadap keputusan pembelian.

Hasil penelitian ini relevan dengan penelitian yang dikemukakan oleh Gilang Ramadhan (2014) yang berjudul Pengaruh Desain Produk dan Harga terhadap Keputusan Pembelian Tas Carrier Eiger di Jakarta, menunjukkan bahwa desain produk secara parsial berpengaruh signifikan terhadap keputusan pembelian.

Nilai koefisien korelasi antara harga dengan keputusan pembelian sebesar 0,273. Nilai koefisien korelasi yang positif menunjukkan bahwa harga dengan keputusan pembelian memiliki hubungan yang positif. Artinya, terjangkaunya harga yang ditawarkan Motor Yamaha NMax di Fortuna Motor Tasikmalaya maka akan semakin tinggi pula keputusan pembelian Motor Yamaha NMax di Fortuna Motor Tasikmalaya, dan begitu sebaliknya. Sedangkan besar pengaruh ragam produk terhadap keputusan pembelian secara parsial sebesar 7,45\% $[\mathrm{Kd}$ $\left.=(0,273)^{2} \times 100 \%\right]$.

Untuk mengetahui signifikansi pengaruh harga secara parsial terhadap keputusan pembelian dilihat dengan cara membandingkan nilai $t_{\text {tabel }}$ dengan $t_{\text {hitung. }}$. Hasil perhitungan memberikan nilai $t_{\text {hitung }}=2,798$ dan $t_{\text {tabel }}=1,98447(\alpha=5 \%)$ maka nilai $t_{\text {hitung }}$ maka nilai $t_{\text {hitung }}>t_{\text {tabel }}$ atau 2,798>1,98447 atau dapat juga dilihat dari nilai Sig. 0,006 hasil perhitungan SPSS Versi 24 yang lebih kecil dari 0,05 (nilai $\alpha=5 \%$ ). Dengan demikian Ho ditolak atau Ha diterima, yang berarti bahwa harga secara parsial berpengaruh signifikan terhadap keputusan pembelian.

Hasil penelitian ini relevan dengan penelitian yang dikemukakan oleh Ferdy Hostiadi Martadinata (2014) Pengaruh Desain produk, Harga terhadap keputusan pembelian Produk Sepatu Futsal Merk Adidas, menunjukkan bahwa harga secara parsial berpengaruh signifikan terhadap keputusan pembelian. 


\section{KESIMPULAN}

\section{Simpulan}

1. Desain produk, harga dan keputusan pembelian Motor Yamaha NMax di Fortuna Motor Tasikmalaya sudah baik dan memenuhi standar yang diinginkan oleh konsumen, desain produk yang dimiliki oleh Motor Yamaha NMax di Fortuna Motor Tasikmalaya memberikan kesan yang baik dan positif yang dimiliki oleh Motor Yamaha NMax di Fortuna Motor Tasikmalaya. Semakin baik desain produk maka diharapkan konsumen akan merasa senang sehingga timbul kesetiaan terhadap Motor Yamaha NMax di Fortuna Motor Tasikmalaya. Harga juga berkategori terjangkau artinya hal ini menunjukan Motor Yamaha NMax di Fortuna Motor Tasikmalaya terjangkau dan memenuhi standar dalam penentuan harga yang dimiliki oleh Motor Yamaha NMax di Fortuna Motor Tasikmalaya.

2. Berdasarkan hasil penelitian bahwa adanya pengaruh yang signifikan secara simultan dari dua variabel yaitu desain produk dan harga terhadap keputusan pembelian. Hal ini menunjukan bahwa tinggi rendahnya keputusan pembelian konsumen dapat dipengaruhi oleh desain produk dan harga Motor Yamaha NMax di Fortuna Motor Tasikmalaya.

3. Berdasarkan hasil penelitian bahwa adanya pengaruh yang signifikan secara parsial antara desain produk dan harga terhadap keputusan pembelian Motor Yamaha NMax di Fortuna Motor Tasikmalaya.

\section{Saran}

Berdasarkan simpulan diatas berikut ini dikemukakan beberapa saran, diantaranya :

1. Berdasarkan hasil bahwa variabel desain produk yang paling rendah pengaruhnya, sehingga perusahaan harus meningkatkan desain produk sehingga konsumen merasa puas ketika menggunakan desain produk yang ditawarkan oleh Motor Yamaha NMax di Fortuna Motor Tasikmalaya.

2. Berdasarkan hasil bahwa variabel harga yang paling tinggi pengaruhnya, sehingga perusahaan harus mempertahankan skema penentuan harga dan harus 
lebih bijak dalam menentukan jumlah harga Motor Yamaha NMax di Fortuna Motor Tasikmalaya.

1. Bagi peneliti selanjutnya, dapat menambah penggunaan variabel-variabel lain yaitu produk, presepsi harga dan citra merek (Aditiya, 2012), sehingga dapat memperbaiki kekurangan yang ada dalam penelitian ini.

\section{DAFTAR PUSTAKA}

Daryanto, (2011). Sari Kuliah Manajemen Pemasaran dan Pemasaran Jasa, Bandung: PT sarana Tutorial Nurani Sejahtera.

Djatmiko, T., Pradana, R. 2015. Brand image and product price; its impact for Samsung smartphone purchasing decision. Prcedia - Social and Behavioral Sciences, 219, 221-227.

Kotler Armstrong. 2012. Marketing. edisi 13. Jakarta: Erlangga.

Kotler, Philip and Kevin Lane Keller. 2012. Marketing Management 13. New Jersey: Pearson Prentice Hall, Inc. 